\title{
Pedigree analysis and inbreeding effects on calving traits in large dairy herds in Germany
}

\author{
D. Hinrichs ${ }^{1}$ and G. Thaller \\ Institute of Animal Breeding and Husbandry, Christian-Albrechts-University, D-24098 Kiel, Germany
}

\begin{abstract}
A pedigree analysis was carried out for a subset of the German Holstein population with respect to the effective number of founders and the ancestors with the highest effect on 2 defined reference populations. Reference population 1 contained animals born between 1998 and $2002(\mathrm{n}=19,537)$, and reference population 2 included animals born between 2003 and 2007 ( $\mathrm{n}=$ 19,060). The pedigree file included 73,946 animals in total. The effective number of founders was 111.3 and 92.8 in reference populations 1 and 2, respectively. In reference population $1,52.22 \%$ of the gene pool could be explained by 10 ancestors. In reference population 2 , the 10 ancestors with the greatest effect contributed $57.22 \%$ of the gene pool. The effect of inbreeding on birth weight, calving ease, and stillbirth was also analyzed in this study. Two models were used to estimate the effect of inbreeding. One model fitted inbreeding as a regression on the inbreeding coefficient of the dam, whereas the other model fitted inbreeding as a regression on the inbreeding coefficient of the calf. Phenotypic data for this study were collected on 3 large commercial milk farms. Data recording took place from February 1998 to December 2008 and 36,623 calving events were recorded; $8.19 \%$ of the calves died at or within $48 \mathrm{~h}$ after calving. All calves were weighed after birth and the average birth weight was $43 \mathrm{~kg}$ for calves born alive and $42 \mathrm{~kg}$ for stillborn calves. Calving ease was recorded on a scale between 1 and 4 . The distribution of scores was $69.81,21.02,8.96$, and $0.22 \%$, ranked 1 (without assistance or assistance by 1 person), 2 (assistance by 2 or more persons or mechanical assistance), 3 (veterinary assistance), and 4 (operation), respectively, on the calving-ease scale. Twins were excluded from all analyses. Dam inbreeding had no significant effect on the traits of this study. The inbreeding coefficient of the calf had no significant effect on birth weight and calving ease but showed a significant effect on stillbirth:
\end{abstract}

Received December 16, 2010.

Accepted April 29, 2011.

${ }^{1}$ Corresponding author: dhinrichs@tierzucht.uni-kiel.de the risk of stillbirth was found to increase by $0.22 \%$ per $1 \%$ increase of the inbreeding coefficient of the calf.

Key words: inbreeding effect, calving trait, pedigree analysis

\section{INTRODUCTION}

Inbreeding occurs when animals mated to each other have common ancestors and is unavoidable in commercial breeding programs in dairy cattle. Consequences of inbreeding include genetic drift, loss of heterozygosity, and decrease in genetic variance. The trend in inbreeding, which can be observed with the analysis of pedigree information, is one way to quantify the rate of genetic drift. Another way to assess genetic drift is to analyze the probability of gene origin by tracing the genetic contribution of founders or ancestors. Boichard et al. (1997) described the different approaches using the probability of gene origin and presented the application of these approaches for 3 different French cattle populations.

Sørensen et al. (2005) examined inbreeding trends and analyzed the pedigree of 3 Danish cattle breeds to assess genetic diversity. The pedigree of Irish beef and dairy cattle was analyzed by Mc Parland et al. (2007a).

The decrease in mean phenotypic performance observed in inbred animals is referred to as inbreeding depression (Falconer and Mackay, 1996) and is generally greater in traits associated with fitness and survival. In dairy cattle, such traits are collectively referred to as functional traits (Groen et al., 1997).

With respect to SCC as an indicator of udder health, some authors (Biffani et al., 2002; Sørensen et al., 2006) found increased SCC with increased inbreeding, whereas Gulisija et al. (2007) could not detect a significant effect of inbreeding on SCC. Negative effects of inbreeding on fertility and survival related traits have been reported by Smith et al. (1998), Thompson et al. (2000), and Sewalem et al. (2006).

Although several papers have been published about calving difficulty and stillbirth (Steinbock et al., 2003; Hansen et al., 2004a,b) most have not considered the effect of inbreeding. Adamec et al. (2006) reported on the effect of inbreeding of the dam on dystocia and 
stillbirth in US Holsteins and showed increased calving difficulty and stillbirth as a consequence of increased inbreeding. Mc Parland et al. (2007b) also reported deleterious effects of inbreeding on dystocia and stillbirth in the Irish Holstein-Friesian population. Inbreeding depression on female fertility and calving ease in Spanish dairy cattle was estimated by González-Recio et al. (2007), using an alternative measurement of inbreeding describing the inbreeding rate for each animal. These authors found that inbred cows had lower pregnancy and higher dystocia rates compared with low or noninbred cows.

The aim of the present study was to carry out a pedigree analysis of German Holsteins with respect to the number of founders, ancestors, and number of effective founder genomes, and to analyze the effect of maternal and fetal inbreeding on birth weight, calving ease, and stillbirth.

\section{MATERIALS AND METHODS}

\section{Phenotypic Data and Pedigree Information}

Phenotypic data for this study were collected between February 1998 and December 2008 on 3 large commercial milk farms with an average herd size of 3,200 German Holstein cows. During that time, 36,623 calving events were recorded on the farms, with the lactation number of the dams ranging from 1 to 11 . For statistical analyses, lactation numbers 3 and higher were combined into a single group. The animals in the data set descended from 1,380 different sires and the average number of offspring per sire was 30.4. In this study, all calves born dead or which died within $48 \mathrm{~h}$ after calving were defined as stillborn and stillbirth was treated as a binary trait $(1=$ stillbirth occurred or $0=$ no stillbirth occurred). The rate of stillbirth was $8.19 \%$. Calves (live and stillborn) were weighed immediately after birth and the average birth weight was $43 \mathrm{~kg}$ for calves born alive and $42 \mathrm{~kg}$ for stillborn calves. Calving ease was recorded according to the official scale of the Arbeitsgemeinschaft Deutscher Rinderzüchter (ADR; umbrella organization of cattle production in Germany), as described in Table 1. Of the 36,623 calv- ings, only 78 had no information on calving ease. The remaining 36,545 calves were $69.81,21.02,8.96$, and $0.22 \%$, ranked 1 (without assistance or assistance by 1 person), 2 (assistance by 2 or more persons or mechanical assistance), 3 (veterinary assistance), and 4 (operation), respectively, on the calving-ease scale. Twins (n $=990$ ) were excluded from all analyses and, therefore, not included in the 36,623 calving events. A pedigree file was constructed in collaboration with Vereinigte Informationssysteme Tierhaltung w.V. (VIT, Verden, Germany), the official computation center responsible for breeding value estimation for German Holsteins, based on animals born on data-recording farms before February 1998 and still alive, and the 36,623 animals born after February 1998. This pedigree file included 73,946 animals and went back to 1906, although most animals were born after 1950 . The pedigree included 27,375 males, 46,396 females, and 175 animals with unknown sex, but these animals were not born on the data-recording farms. These animals descended from 7,119 different sires and 37,931 different dams. It should be noted that the pedigree of this study also included all stillborn animals. For these animals, a unique identification number was constructed, including information about the dam and day of birth.

\section{Pedigree Analysis}

Two reference populations were defined for pedigree analysis. Reference population 1 included animals born between 1998 and 2002, whereas reference population 2 included animals born between 2003 and 2007. The number of animals in reference populations 1 and 2 was 19,537 and 19,060, respectively. For pedigree analysis, the software package Pedig (Boichard, 2002) was used. This software includes a set of independent programs to calculate probabilities of gene origin, relationships and inbreeding coefficients, and to characterize the quality of pedigree information. Inbreeding coefficients were calculated from the pedigree using the method described by Meuwissen and Luo (1992). The number of complete generation equivalents for each individual was calculated as:

Table 1. Definition of calving ease, according to $\mathrm{ADR}^{1}$

\begin{tabular}{ll}
\hline $\begin{array}{l}\text { Calving-ease } \\
\text { scale }\end{array}$ & Definition \\
\hline 1 & Without assistance or assistance by 1 person \\
2 & Assistance by 2 or more persons or mechanical assistance \\
3 & Veterinary assistance \\
4 & Operation \\
${ }^{1} \mathrm{ADR}=$ Arbeitsgemeinschaft Deutscher Rinderzüchter (umbrella organization of cattle production in \\
Germany).
\end{tabular}




$$
G_{j}=\sum_{i=1}^{n_{i}} \frac{1}{2 g^{g_{i j}}},
$$

where $G_{j}=$ complete generation equivalent for animal $j ; n_{i}=$ number of known ancestors in generation $i$; and $g=$ number of known generations for individual $j$.

Founders were defined as animals with unknown parents. If an animal had one unknown parent, the unknown parent was considered a founder, which implied multiplying the contribution of these animals by 0.5 . The contribution of a founder to a reference population depended on its use in the past and, therefore, information given by the total number of founders was limited.

This problem was avoided by the calculation of the effective number of founders. Lacy (1989) defined the effective number of founders as the number of equally contributing founders expected to produce the same genetic diversity in the population under study. The effective number of founders was computed as

$$
f_{e}=\left(\sum_{i=1}^{N_{f}} q_{i}^{2}\right)^{-1}
$$

where $f_{e}=$ effective number of founders; $N_{f}=$ total number of founders; and $q_{i}=$ genetic contribution of the $i$ th founder to the reference population

The genetic contribution of an animal quantifies its contribution to a reference population and was calculated as described by Boichard et al. (1997). Because bottlenecks in the pedigree are not considered when calculating the effective number of founders, Boichard et al. (1997) proposed calculating the effective number of ancestors. This is a measure of genetic diversity for populations which accounts for loss of allelic diversity. The effective number of ancestors was calculated as

$$
f_{a}=\left(\sum_{i=1}^{N_{a}} p_{i}^{2}\right)^{-1},
$$

where $f_{a}=$ effective number of ancestors; $N_{a}=$ total number of ancestors; and $p_{i}=$ marginal genetic contribution of the $i$ th ancestor.

For computation of the marginal genetic contributions of ancestors, the ancestor with the highest genetic contribution to the reference population was chosen. Thereafter, genetic contributions of all other ancestors were calculated conditional on the genetic contribution of the chosen ancestor. Another measurement for genetic diversity of a reference population is the effec- tive number of founder genomes, which accounts for unequal contributions of founders and random loss of alleles caused by genetic drift during bottlenecks (Lacy, $1989,1995)$. The following equation was used to calculate the effective number of founder genomes:

$$
f_{g}=\left(\sum_{i=1}^{N_{f}} \frac{q_{i}^{2}}{r_{i}}\right)^{-1}
$$

where $f_{g}=$ effective number of founder genomes; $N_{f}=$ total number of founders; $q_{i}=$ genetic contribution of the $i$ th founder to the reference population; and $r_{i}=$ proportion of founder genes in the reference population.

The proportion of founder genes, $r_{i}$, is the expected proportion of founder $i$ 's alleles that have been retained within the descendant population, and was calculated by gene drop computer simulation, as described by Boichard (2002).

\section{Estimation of Variance Components and Inbreeding Effects}

The software package SAS (SAS Institute, 1999) was used for data preparation and ASREML (Gilmour et al., 1999) was used for the estimation of variance components and effects of inbreeding on birth weight, calving ease, and stillbirth. For calving ease and stillbirth, the logit link function of the form $\mu /(1-\mu)$ was used. Inbreeding effects were estimated as a regression, either on the inbreeding coefficient of the dam, or the inbreeding coefficient of the calf. The following model was used for the estimation of variance components and inbreeding effects:

$$
\begin{aligned}
y_{i j k l m n}=\mu+ & h k s_{i}+\ln _{j}+\operatorname{sex}_{k}+\beta F+\operatorname{dam}_{l} \\
& + \text { animal }_{m}+e_{i j k l m n}
\end{aligned}
$$

where $y_{i j k l m n}=$ observation (birth weight, calving ease, or stillbirth); $\mu=$ overall mean; $h k s_{i}=$ fixed effect of $i$ th herd-calving-year-season $(i=1, \ldots, 122) ; \ln r_{j}=$ fixed effect of $j$ th lactation $(\mathrm{j}=1, \ldots, 3) ; \operatorname{sex}_{k}=$ fixed effect of $k$ th sex of the calf $(\mathrm{k}=1$ or 2$) ; \beta F=$ regression coefficient on inbreeding coefficient of the dam or of the calf; $d a m_{l}=$ random effect of the $l$ th dam $(l=1, \ldots$, 16,463); animal $_{m}=$ random effect of the $m$ th animal $(\mathrm{m}$ $=1, \ldots, 73,946)$; and $e_{i j k l m n}=$ random residual effect.

\section{RESULTS}

The maximal inbreeding coefficient was 0.39 and 51,334 of 73,946 animals were inbred with an average 
Table 2. Number of animals born, average number of complete generation equivalents (GE), and average fraction of known ancestors during the last 10 generations (Aver. Fract. Ten Gen.) by birth year and sex

\begin{tabular}{|c|c|c|c|c|c|c|}
\hline $\begin{array}{l}\text { Year of } \\
\text { birth }\end{array}$ & \multicolumn{3}{|c|}{ Males } & \multicolumn{3}{|c|}{ Females } \\
\hline 1975 & 142 & 2.56 & 26 & 687 & 2.27 & 23 \\
\hline 1980 & 143 & 3.42 & 34 & 705 & 2.91 & 29 \\
\hline 1985 & 145 & 4.13 & 41 & 791 & 3.43 & 34 \\
\hline 2000 & 2,071 & 7.48 & 74 & 1,877 & 7.50 & 75 \\
\hline 2005 & 2,129 & 8.46 & 83 & 1,817 & 8.51 & 84 \\
\hline Total & 5,013 & 5.02 & 50 & 8,542 & 4.61 & 46 \\
\hline
\end{tabular}

inbreeding coefficient of inbred animals of 0.03 . The inbreeding coefficient was below 0.05 , between 0.05 and 0.09 , between 0.10 and 0.14 , and greater than 0.14 for $57.5 \%, 11.5 \%, 0.3 \%$, and $0.1 \%$ of the animals, respectively.

The change of average inbreeding coefficients over time is illustrated in Figure 1. The average inbreeding coefficient of animals born in 1970 was 0.002 and increased to 0.049 for animals born in 2008. Also, the average inbreeding coefficient of cows born in the 3 data-recording farms increased from 0.01 (1995) to 0.05 (2008). The inbreeding coefficients of stillborn animals and animals born alive were compared, as shown in Figure 2. For both groups, the average inbreeding coefficient increased over time. However, the average inbreeding coefficients of stillborn calves were higher compared with calves born alive throughout the duration of the study.

Table 2 summarizes the average number of complete generation equivalents and the average fraction of known ancestors when the pedigree was traced back for 10 generations. Table 2 also shows the number of males and females born between 1970 and 2005. Male

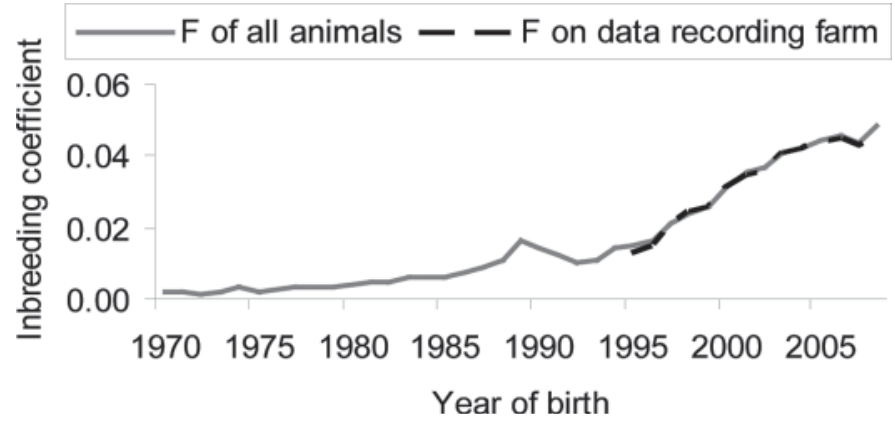

Figure 1. Change in average inbreeding coefficient $(\mathrm{F})$ for animals $(\mathrm{n}=61,842)$ with known parents born between 1970 and 2008 and females $(\mathrm{n}=23,699)$ born on data-recording farms between 1995 and 2008. calves born on the 3 data-recording farms in 2000 and 2005 were included, explaining the increased number of males in those years. Similarly, the number of females increased in 1995, 2000, and 2005 because of the inclusion of female calves born on data-recording farms. In both sexes, the average number of complete generation equivalents and the average fraction of known ancestors for a 10-generation pedigree increased with time. Overall, the mean complete generation equivalent was 4.82 and the mean fraction of known ancestors for a 10 -generation pedigree was $48 \%$.

The effective number of founders, ancestors, and founder genomes, and number of ancestors accounting for 50,75 , and $95 \%$ of the gene pool of the 2 reference populations are summarized in Table 3 . Table 4 shows the marginal genetic contribution of the 10 ancestors with the greatest effect on both populations. These ancestors accounted for $52.22 \%$ and $57.22 \%$ of the genetic diversity in the 2 populations. If the number of ancestors were extended to 50, then 75.61 and $81.58 \%$ of the gene pool would be explained by these ancestors in reference populations 1 and 2 , respectively.

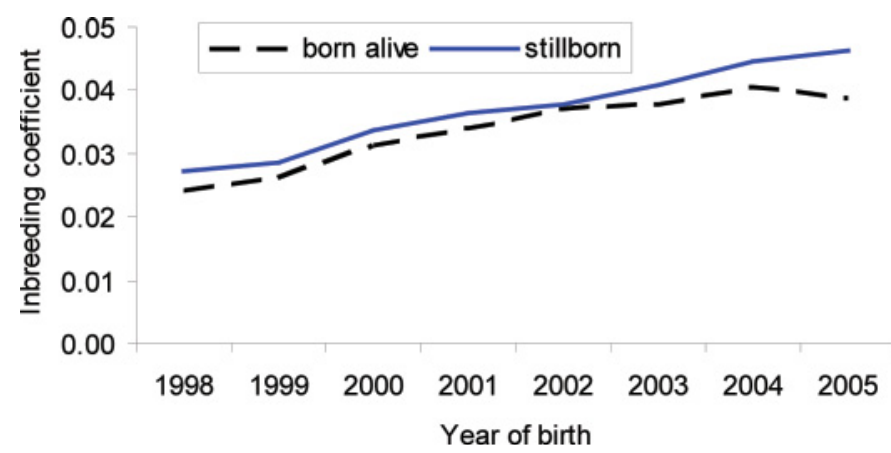

Figure 2. Comparison of the average inbreeding coefficients of calves born alive and stillborn calves. Color version available in the online PDF. 
Table 3. Effective number of founders, ancestors and founder genomes, and number of ancestors accounting for 50,75 , and $95 \%$ of the gene pool of the two reference populations (Ref. pop.) ${ }^{1}$

\begin{tabular}{lcc}
\hline Item & $\begin{array}{c}\text { Ref. } \\
\text { pop. } 1\end{array}$ & $\begin{array}{c}\text { Ref. } \\
\text { pop. } 2\end{array}$ \\
\hline Effective number of founders & 111.3 & 92.8 \\
Effective number of ancestors & 23.40 & 19.23 \\
Effective number of founder genomes & 14.10 & 11.01 \\
Number of ancestors explaining 50\% of the gene pool & 9 & 7 \\
Number of ancestors explaining 75\% of the gene pool & 55 & 30 \\
Number of ancestors explaining 95\% of the gene pool & 745 & 328 \\
\hline
\end{tabular}

${ }^{1}$ Reference population $1(\mathrm{n}=19,537)$ includes animals born between 1998 and 2002 and reference population $2(\mathrm{n}=19,060)$ includes animals born between 2003 and 2007.

Estimated variance components and heritabilities for birth weight, calving ease, and stillbirth are summarized in Table 5 from the model including calf inbreeding. As expected, the highest heritability was estimated for birth weight $\left(h^{2}=0.58\right)$ and the lowest for stillbirth $\left(h^{2}\right.$ $=0.05)$. Variance components were similar when the inbreeding coefficient of the dam was modeled (results not shown).

The effects of inbreeding on the 3 calving traits are summarized in Table 6. No significant $(P>0.01)$ inbreeding effects of the dam were found on any of the traits. The effect of inbreeding of the calf was not significant on birth weight or calving ease. However, a significant $(P<0.01)$ inbreeding effect was estimated on stillbirth and the risk of stillbirth increased by $0.22 \%$ per $1 \%$ increase of the inbreeding coefficient of the calf.

\section{DISCUSSION}

The effects of inbreeding have been analyzed intensively in animal breeding, evolutionary biology, and conservation genetics. However, several questions relating to the phenomena of inbreeding and inbreeding depression remain unanswered. In this paper, pedigree information of 3 large dairy farms was analyzed, and the effects of inbreeding on birth weight, calving ease, and stillbirth were estimated.

Trends in inbreeding may describe the extent of past genetic drift. An alternative would be to analyze the probabilities of gene origin for a defined reference population. Both genetic drift and gene origin methods were applied in this study and 2 different reference populations were used, which allowed the determination of the effect of the reference population.

One important question is how to manage inbreeding in commercial breeding programs. Meuwissen and Sonesson (1998) extended the method of Meuwissen (1997) to breeding programs with overlapping generations. The first step in implementing such new selection methods is a brief analysis of the current pedigree. This provides valuable information about the history of the population and the quality of pedigree data. The pedigree analysis in the present study revealed good pedigree data quality (Table 2). For animals born in 2005 , the average fraction of known ancestors for the last 5 generations was $99 \%$ for females and $98 \%$ for males. Cassell et al. (2003a) reported that $97.7 \%$ of the pedigrees in US Holsteins were complete for the

Table 4. Marginal genetic contribution (\%) of the 10 ancestors with the greatest effect on the 2 reference populations (Ref. pop.) $)^{1}$

\begin{tabular}{llccc}
\hline $\begin{array}{l}\text { Name of } \\
\text { ancestor }\end{array}$ & $\begin{array}{l}\text { Interbull ID } \\
\text { of ancestor }\end{array}$ & $\begin{array}{c}\text { Year of birth } \\
\text { of ancestor }\end{array}$ & $\begin{array}{c}\text { Ref. } \\
\text { pop. } 1\end{array}$ & $\begin{array}{c}\text { Ref. } \\
\text { pop. 2 }\end{array}$ \\
\hline Elevation & 840000001491007 & 1965 & 14.3 & 15.76 \\
Chief & 840000001427381 & 1962 & 9.82 & 10.53 \\
Ivanhoe & 840000001189870 & 1952 & 5.08 & 2.44 \\
Cleitus & 840000001879085 & 1981 & 4.70 & 3.85 \\
Bell & 840000001667366 & 1974 & 3.76 & 6.62 \\
Dam of Valerian & 840000006781299 & 1966 & 3.73 & 3.86 \\
Blackstar & 840000001929410 & 1983 & 3.64 & 4.96 \\
Starbuck & 124000000352790 & 1979 & 3.25 & 4.88 \\
Aerostar & 124000000383622 & 1980 & - & 2.18 \\
Fond Matt & 840000001392858 & 1960 & 2.26 & - \\
Ned Boy & 840000001806201 & 1979 & 1.68 & 2.14 \\
Total & & & 52.22 & 57.22 \\
\hline
\end{tabular}

${ }^{1}$ Reference population $1(\mathrm{n}=19,537)$ includes animals born between 1998 and 2002 and reference population $2(\mathrm{n}=19,060)$ includes animals born between 2003 and 2007. 
Table 5. Estimated variance components for permanent environmental effect $\left(\sigma_{\text {dam }}^{2}\right)$, animal $\left(\sigma_{\text {animal }}^{2}\right)$, residual $\left(\sigma_{e}^{2}\right)$, and heritabilities $\left(\mathrm{h}^{2}\right)$ with standard errors in parentheses

\begin{tabular}{llccc}
\hline Trait & \multicolumn{1}{c}{$\sigma_{\text {dam }}^{2}$} & $\sigma_{\text {animal }}^{2}$ & $\sigma_{e}^{2}$ & $\mathrm{~h}^{2}$ \\
\hline Birth weight (kg) & $1.410(0.18)$ & $14.100(0.62)$ & $11.360(0.36)$ & $0.58(0.02)$ \\
Calving ease (scale 1 to 4) & $0.007(<0.01)$ & $0.016(<0.01)$ & $0.141(<0.01)$ & $0.14(0.01)$ \\
Stillbirth (scale 0 to 1) & $0.001(<0.01)$ & $0.001(<0.01)$ & $0.052(<0.01)$ & $0.05(0.01)$ \\
\hline
\end{tabular}

${ }^{1}$ Calving-ease scale: $1=$ without assistance or assistance by 1 person; $2=$ assistance by 2 or more persons or mechanical assistance; $3=$ veterinary assistance; $4=$ operation.

${ }^{2}$ Stillbirth scale: $0=$ no stillbirth occurred; $1=$ stillbirth occurred.

last 5 generations. The number of complete generation equivalents (Table 2) was higher than that reported by other authors; for example, Sørensen et al. (2005) found a complete generation equivalent of 7.20, 7.36, and 6.77 for Danish Holsteins, Danish Jerseys, and Danish Reds, respectively.

Other measurements providing information about the genetic diversity of a studied population are the effective number of founders, ancestors, and founder genomes. Sørensen et al. (2005) estimated that the effective number of founders was 70 for the Danish Holstein population, which is lower than the effective number of founders estimated here (Table 3). The effective number of founders of the present study agrees with those of Hammami et al. (2007) for the Tunisian Holstein population. The same authors also estimated the effective number of founders for the Holstein population in Luxembourg at 295. However, in dairy cattle, the effective number of ancestors gives better information because it accounts for bottlenecks in the pedigree, which are likely the major cause of gene loss in dairy cattle populations. Similar results were found when comparing the effective number of ancestors in the study (23.40 and 19.23 for reference populations 1 and 2, respectively) with literature reports, with the exception of the Holstein population from Luxembourg, where the effective number of ancestors was 44 (Hammami et al., 2007). For the Tunisian and Danish Holstein populations, this number was 22 and 20.6, respectively (Sørensen et al., 2005; Hammami et al., 2007). Another important reason for the loss of genetic diversity is random genetic drift, which is not taken into account in the effective number of ancestors. However, the effective number of founder genomes may be considered in this regard, as it accounts for all causes of gene loss during segregation. The effective number of founder genomes presented in Table 3 is similar to that reported by Sørensen et al. (2005) for the Danish Holstein population.

Hansen (2006) showed that 2 bulls born in the 1960s accounted for about $30 \%$ of the genes of the US Holstein population in 2005. These 2 bulls were Elevation and Chief and their marginal genetic contribution to the reference populations of this study are shown in Table 4. The marginal genetic contributions of these 2 bulls agreed with those reported by Hansen (2006). Similar genetic contributions by Elevation and Chief were found by Sørensen et al. (2005) and Hammami et al. (2007) for Danish and Tunisian Holsteins, respectively.

One important difference between the present study and previous studies on inbreeding (e.g., Adamec et al. 2006; Mc Parland et al. 2007b) is that that our data was collected under an organized performance test program. The consequences are (1) a smaller number of animals compared with most previous studies and (2) good calving data quality containing information that was not previously available (e.g., birth weight and inbreeding coefficients of stillborn calves).

The change of inbreeding coefficients over time (Figure 1) is in agreement with the results from the Belgian Holstein population (Croquet et al., 2006) and the Danish Holstein population (Sørensen et al., 2005). Higher levels of inbreeding have been observed for the Canadian Holstein population (Sewalem et al., 2006) and for the US Holstein population (Weigel, 2001). A similar change in inbreeding has also been found for other dairy cattle breeds [e.g., Jersey, Brown Swiss, and Ayrshire (Weigel, 2001)]. Unfortunately, no national database reports exist in the literature about inbreeding trends in the German Holstein population.

König and Simianer (2006) compared the inbreeding coefficients of bull dams born in Germany with inbreeding coefficients from commercial cows and found higher inbreeding coefficients for bull dams, which was not the case in the present study (Figure 1). The reason for

Table 6. Effects of inbreeding (F) estimated as regression on each trait (standard errors in parentheses)

\begin{tabular}{lcc}
\hline Trait & $\begin{array}{c}\text { Inbreeding } \\
\text { of dam }\end{array}$ & $\begin{array}{c}\text { Inbreeding } \\
\text { of calf }\end{array}$ \\
\hline Birth weight & $4.10(2.45)$ & $-2.31(2.18)$ \\
Calving ease & $0.21(0.17)$ & $-0.10(0.16)$ \\
Stillbirth & $-0.18(0.09)$ & $0.22(0.09)^{*}$ \\
\hline
\end{tabular}

*Statistically greater than zero $(P<0.01)$. 
this difference is probably that the 2 studies were based on different data sets and none of them actually used national data.

A comparison of inbreeding coefficients from stillborn calves and calves born alive has rarely been described in the literature. The main reason could be that it is very difficult to obtain valid information (e.g., about sires and dams) from stillborn calves. Due to the data structure of the present study it was possible to estimate an inbreeding coefficient for stillborn calves that was consistently higher than that of calves born alive (Figure 2). It should be noted, however, that this difference was not significantly greater than zero $(P>0.05)$.

Significant inbreeding depression was estimated for stillbirth only when the inbreeding coefficient of the calf was considered, whereas the inbreeding coefficient of the dam had no significant effect on stillbirth. Calves of inbred cows tended to have higher birth weight and, as a consequence, showed more calving difficulties, which is in agreement with the results of Adamec et al. (2006). Results of the present study, however, were not statistically significant in this regard.

Despite the limited database of the present study, results show that inbreeding coefficients of stillborn calves could add valuable information to calving traits. Cassell et al. (2003b) analyzed maternal and fetal inbreeding depression for 70-d nonreturn and calving rate in US Holsteins and Jerseys and found small and not consistently significant inbreeding effects. VanRaden and Miller (2006) reported that increased inbreeding of embryos could have negative effects on conception and the survival of the embryo. Thus, if inbreeding has negative effects on conception and the survival of the embryo, it is not surprising that inbreeding also results in an increased risk of stillbirth.

\section{CONCLUSIONS}

Data from an organized performance test program in contract herds was used for a pedigree analysis and the estimation of inbreeding effects. Pedigree analysis showed that inbreeding, management of inbreeding, and genetic diversity will be important points in breeding programs in the future. In addition, the pedigree analysis showed that the studied herds reflected the German Holstein population, as well as other Holstein populations worldwide. Nevertheless, further research must be conducted to develop effective methods for the management of genetic diversity. However, this study showed that contract herds could provide information for this research, if they are large enough. A significant relationship between inbreeding and stillbirth was found, suggesting that the risk of stillbirth increases with increasing inbreeding coefficient of the calf.

\section{ACKNOWLEDGMENTS}

This manuscript has benefited from critical and helpful comments of the Journal of Dairy Science section editor and 2 anonymous reviewers.

\section{REFERENCES}

Adamec, V., B. G. Cassell, E. P. Smith, and R. E. Pearson. 2006. Effects of inbreeding in the dam on dystocia and stillbirths in US Holsteins. J. Dairy Sci. 89:307-314.

Biffani, S., A. B. Samoré, and F. Canavesi. 2002. Inbreeding depression for production, reproduction and functional traits in Italian Holstein cattle. Pages 183-186 in Proc. 7th World Congr. Genet. Appl. Livest. Prod., Montpellier, France. INRA, Montpellier, France.

Boichard, D. 2002. Pedig: A Fortran package for pedigree analysis suited to large populations. Comm. 28-13 in Proc. 7th World Congr. Genet. Appl. to Livest. Prod., Montpellier, France. INRA, Montpellier, France.

Boichard, D., L. Maignel, and É. Verrier. 1997. The value of using probabilities of gene origin to measure genetic variability in a population. Genet. Sel. Evol. 29:5-23.

Cassell, B. G., V. Adamec, and R. E. Pearson. 2003a. Effect of incomplete pedigrees on estimates of inbreeding and inbreeding depression for days to first service and summit milk yield in Holsteins and Jerseys. J. Dairy Sci. 86:2967-2976.

Cassell, B. G., V. Adamec, and R. E. Pearson. 2003b. Maternal and fetal inbreeding depression for 70-day nonreturn and calving rate in Holsteins and Jerseys. J. Dairy Sci. 86:2977-2983.

Croquet, C., P. Mayeres, A. Gillon, S. Vanderick, and N. Gengler. 2006. Inbreeding depression for global and partial economic indexes, production, type, and functional traits. J. Dairy Sci. 89:2257-2267.

Falconer, D. S., and T. F. C. Mackay. 1996. Introduction to Quantitative Genetics. Longman, Harlow Essex, UK.

Gilmour A.R., B. R. Cullis, S. J. Welham, and R. Thompson. 1999. ASREML Reference Manual. NSW Agriculture Biometric Bulletin No. 3. NSW Agriculture, Orange, Australia.

González-Recio, O., E. López de Maturana, and J. P. Gutiérrez. 2007. Inbreeding depression on female fertility and calving ease in Spanish dairy cattle. J. Dairy Sci. 90:5744-5752.

Groen, A. F., T. Steine, J.-J. Colleau, J. Pedersen, J. Pribyl, and N. Reinsch. 1997. Economic values in dairy cattle breeding, with special reference to functional traits. Reports of an EAAP-working group. Livest. Prod. Sci. 49:1-21

Gulisija, D., D. Gianola, and K. A. Weigel. 2007. Nonparametric analysis of the impact of inbreeding on production in Jersey cows. J. Dairy Sci. 90:493-500.

Hammami, H., C. Croquet, J. Stoll, B. Rekik, and N. Gengler. 2007. Genetic diversity and joint-pedigree analysis of two importing Holstein populations. J. Dairy Sci. 90:3530-3541.

Hansen, L. B. 2006. Monitoring the worldwide genetic supply for dairy cattle with emphasis on managing crossbreeding and inbreeding. Proc. 8th World Congr. Genet. Appl. Livest. Prod., Bello Horizonte, Brazil. CD-ROM Communication No.01-01.

Hansen, M., M. S. Lund, J. Pedersen, and L. G. Christensen. 2004a. Genetic parameters for stillbirth in Danish Holstein cows using a Bayesian threshold model. J. Dairy Sci. 87:706-716.

Hansen, M., I. Misztal, M. S. Lund, J. Pedersen, and L. G. Christensen. 2004b. Undesired phenotypic and genetic trend for stillbirth in Danish Holsteins. J. Dairy Sci. 87:1477-1486.

König, S., and H. Simianer. 2006. Approaches to the management of inbreeding and relationship in the German Holstein dairy cattle population. Livest. Sci. 103:40-53.

Lacy, R. C. 1989. Analysis of founder representation in pedigrees: Founder equivalents and founder genome equivalents. Zoo Biol. 8:111-123.

Lacy, R. C. 1995. Clarification of genetic terms and their use in the management of captive populations. Zoo Biol. 14:565-577. 
Mc Parland, S., J. F. Kearney, M. Rath, and D. P. Berry. 2007a. Inbreeding trends and pedigree analysis of Irish dairy and beef cattle populations. J. Anim. Sci. 85:322-331.

Mc Parland, S., J. F. Kearney, M. Rath, and D. P. Berry. 2007b. Inbreeding effects on milk production, calving performance, fertility, and conformation in Irish Holstein-Friesians. J. Dairy Sci. 90:4411-4419.

Meuwissen, T. H. E. 1997. Maximizing the response of selection with a predefined rate of inbreeding. J. Anim. Sci. 75:934-940.

Meuwissen, T. H. E., and Z. Luo. 1992. Computing inbreeding coefficient in large populations. Genet. Sel. Evol. 24:305-313.

Meuwissen, T. H. E., and A. K. Sonesson. 1998. Maximizing the response of selection with predefined rate of inbreeding: Overlapping generations. J. Anim. Sci. 76:2575-2583.

SAS Institute. 1999. SAS/STAT User's Guide. Version 8. SAS Institute Inc., Cary, NC.

Sewalem, A., G. J. Kistemaker, F. Miglior, and B. J. Van Doormaal. 2006. Analysis of inbreeding and its relationship with functional longevity in Canadian dairy cattle. J. Dairy Sci. 89:2210-2216.

Smith, L. A., B. G. Cassell, and R. E. Pearson. 1998. The effects of inbreeding on the lifetime performance of dairy cattle. J. Dairy Sci. 81:2729-2737.
Sørensen, A. C., P. Madsen, M. K. Sørensen, and P. Berg. 2006. Udder health shows inbreeding depression in Danish Holsteins. J. Dairy Sci. 89:4077-4082.

Sørensen, A. C., M. K. Sørensen, and P. Berg. 2005. Inbreeding in Danish dairy cattle breeds . J. Dairy Sci. 88:1865-1872.

Steinbock, L., A. Näsholm, B. Berglund, K. Johansson, and J. Philipsson. 2003. Genetic effects on stillbirths and calving difficulty in Swedish Holsteins at first and second calving. J. Dairy Sci. $86: 2228-2235$.

Thompson, J. R., R. W. Everett, and N. L. Hammerschmidt. 2000. Effects of inbreeding on production and survival in Holsteins. J. Dairy Sci. 83:1856-1864.

VanRaden, P. M., and R. H. Miller. 2006. Effects of nonadditive genetic interactions, inbreeding, and recessive defects on embryo and fetal loss by seventy days. J. Dairy Sci. 89:2716-2721.

Weigel, K. A. 2001. Controlling inbreeding in modern breeding programs. J. Dairy Sci. 84(E. Suppl.):E177-E184. 